\title{
Fate of the epsilon phase in the Oklo natural reactors
}

\section{S. UTSUNOMIYA AND R.C. EWING}

Department of Geological Sciences, University of Michigan, Ann Arbor, Michigan 48109-1063 USA. (utu@umich.edu)

In spent nuclear fuel (SNF), the micron- to submicron-sized epsilon phase (Mo-Ru-Pd-Tc-Rh) is an important host of ${ }^{99} \mathrm{Tc}$ which has a long half life $\left(2.13 \times 10^{5}\right.$ years $)$ and can be an important contributor to dose in safety assessments of nuclear waste repositories. In addition, $\mathrm{Tc}$ is predominantly present as $\mathrm{TcO}_{4}{ }^{-}$under oxidizing conditions at wide range of $\mathrm{pH}$, weakly adsorbed onto mineral surfaces, and unlikely to be incorporated into alteration uranyl minerals. In the Oklo natural reactor $(2.0 \mathrm{Ga})$, essentially all of the ${ }^{99} \mathrm{Tc}$ has decayed to ${ }^{99} \mathrm{Ru}$. Thus, this study focuses on $\mathrm{Ru}$ and the other metals of the epsilon phase in order to investigate the occurrence and the fate of the epsilon phase during the corrosion of this natural SNF. Samples from reactor zone $(\mathrm{RZ})-10(836,819,687)$; from $\mathrm{RZ}-13(864,910)$; were investigated using TEM (transmission electron microscopy).

Within the $\mathrm{UO}_{2}$ matrix, a Bi-Pd particle $\left(40-60 \mathrm{~nm}\right.$ ), froodite, $\mathrm{PdBi}_{2}$, was observed with trace amounts of $\mathrm{As}, \mathrm{Fe}$, and Te surrounded by an amorphous $\mathrm{Pb}$-rich area. $(\mathrm{Pd}, \mathrm{Rh})_{2} \mathrm{As}$, palladodymite or rhodarsenide, was observed (400-500 $\mathrm{nm}$ in size). Ruthenarsinite, (Ru,Ni)As, was identified in most samples: with a representative composition of As, 59.9: $\mathrm{Co}, 2.5: \mathrm{Ni}, 5.2 ; \mathrm{Ru}, 18.6 ; \mathrm{Rh}, 8.4$; $\mathrm{Pd}, 3.1 ; \mathrm{Sb}, 2.4$ in atomic percent. The particles diameters are a few hundred nanometers and, in most cases, surrounded by a $\mathrm{Pb}$-rich phase $(400-500 \mathrm{~nm})$. Typically, the ruthenarsenite does not occur as single particle but an aggregate of $\sim 200 \mathrm{~nm}$-sized particles. Some Ru-particles revealed a complex phase separation within the grain such as a Ru-particle (600-700 nm) with $\mathrm{Pb}$ at the core of the particle and enrichment of $\mathrm{Ni}, \mathrm{Co}$, and $\mathrm{As}$ at the rim. Some ruthenarsenite crystals were embedded in chlorite immediately adjacent to uraninite. A few particles were still coated by $\mathrm{Pb}$. These results suggest a history for the epsilon phases: (i) The original epsilon phase was transformed to, in most cases, ruthenarsenite. (ii) All Mo and most of the Tc were released from the epsilon phase. Some portion of the other metals was also leached and provided a space for a precipitation of $\mathrm{PbS}$ between the ruthenarsenite and uraninite. (iii) Once the uraninite matrix dissolved, the epsilon particles were released and sometimes captured within adjacent alteration minerals.

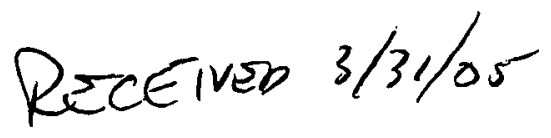

